\title{
Fuzzy Rule Based Inference System for Implementation of Naval Military Mission
}

\author{
Rashmi Singh* \\ Babasaheb Bhimrao Ambedkar University (A Central University) Vidya Vihar, Raebarli Road Lucknow, 226025, UP, \\ India \\ E-mail: rshmi08@gmail.com \\ Vipin Saxena \\ Babasaheb Bhimrao Ambedkar University (A Central University) Vidya Vihar, Raebarli Road Lucknow, 226025, UP, \\ India \\ E-mail: vsax1@rediffmail.com
}

Received: 18 November 2017; Accepted: 16 January 2018; Published: 08 April 2018

\begin{abstract}
Naval military units are convoluted frameworks required to work in specific time periods in seaward assignments where support operations are radically restricted. A decline at the time of mission is an analytical fact that can radically impact the mission achievement. The choice of changing a unit to a mission subsequently requires complex judgments including data about the well being status of hardware and the natural conditions. The present system expects to help the choice about changing a unit to a mission considering that ambiguity and unpredictability of information by methods of fuzzy concepts and imitates the selection procedure of a human trained by means of a rule-based inference system. A numerical application is introduced to demonstrate the viability of the approach.
\end{abstract}

Index Terms-Inference system, fuzzy concept, analytical fact, naval military, hardware.

\section{INTRODUCTION}

A lot of works has been done by researchers on inference system but it is limited towards fuzzy rule based inference system and the present work is an attempt in this direction. Let us explain some important references. Singh K. proposed modified adaptive modulation technique in this article. The proposed technique adapts nature of communication based on present modulation sequence, code rate, bit error rate and signal to noise ratio [1]. Mustapha $\mathrm{S}$. et al. introduced a neuro fuzzy networks sequential adaptive fuzzy inference system (SAFIA) for the evaluation of performance of controlled robot manipulation [2]. Olugo et al. developed a fuzzy rule base system by using visual basic.Net. They also described the fuzzy rules and arithmetic [3]. Akgun et al. have studied landslide susceptibility mapping using a completely expert opinion based approach which is applied for Sinop (Northern Turkey) region and its close vicinity. A program named as "MamLand" was used for the construction of Mamdani Fuzzy Inference System and employed in MATLAB. Seven conditioning parameters are used in this study that characterizes topographical, geological and environmental conditions. In these studies, 351 landslide locations were used. After completing the data production study, the data was analyzed using a computing approach named as Mamdani type fuzzy inference system [4]. Amindoust et al. have regulated the sustainable supplier selection criteria and sub criteria and proposed a methodology for evaluation and ranking for a given set of suppliers. The fuzzy logic has been applied and a new ranking method named as Fuzzy Inference System (FIS) is proposed for the supplier selection problem [5]. Singh and Chandra presented an Adaptive Network Based Fuzzy Inference System (ANFIS) for the estimation of speed and position of Permanent Magnet Synchronous Generator (PMSG). ANFIS tune estimator is used to estimate the rotor position and its speed accurately against parameter variation. This system consists of two back to back connected invertors in which one is used to controlling the PMSG whereas the other one is used to synchronize the grid. The proposed system is simulated by MATLAB/Slim Power System (SPS) tool box [6]. Büyüközkan, Çifçi here examined the problem to identify a beneficial model based on sustainability principles for supplier selection operation in supply chains. The sustainable supplier evaluation proves an appropriate multi criteria analysis and solution approach because it has the multi criteria nature. During the evaluation process, the decision maker might face various situations like time pressure, lack of expertise in related issues etc.

In this study, authors developed a new strategy which is based on fuzzy analytical network process within multi person decision making under incomplete preference relation and they also analyzed the sustainability of supplier in real life problems by which the validity of model can be evaluated [7]. Farnandez et al. described multiclass classification for linguistic fuzzy rule based classification system and proposed an idea in 
which the original data is decomposed into binary classification problems using the pairwise learning approach (Confronting all pair of classes) and finally obtained an independent fuzzy system for each one of the fuzzy rule based classification system produce an associate degree for both the corresponding classes along with inference process and these values are encoded into a fuzzy preference relation [8]. Ustundag et al. introduced Radio Frequency Identification (RFID) technology by which the chance of visibility is increased through easy tracking and identifying of goods, assets and even living things. The cast and benefits of element were determined with the help of RFID system whereas the accepted increase of customer order is determined in the form of delivery accuracy and delivery time by using fuzzy rule based system. The expected net present value (NPV) of RFID investment is determined with the help of Monte Carlo simulation method [9]. Kurnaz et al. described an Adaptive Neuro Fuzzy Inference System (ANFID) based autonomous flight controller for Unmanned Aerial Vehicles (UAVs). Three fuzzy logic modules are developed to control the location of the UAV in three dimensions space as altitude location, longitude location and latitude location. the Heading, and the speed are controlled with the help of adjustment of the pitch angle, the roll angle and the throttle position of the UAV. MATLABs standard configuration and the Aerosim aeronautical simulation block set are used for the implementation of the framework [10]. Boyacioglu and Avci investigated the predictability of stock market return by using Adaptive Network Based Fuzzy Inference System (ANFIS) and used a model in which the predictability of the return on stock price index of the Istanbul Stock Exchange (ISE) is measured by ANFIS [11]. Aarabi et al. presented a method for automatic detection of seizures in the intracranial EEG recording of the patients which are suffering from medically intractable focal epilepsy. The author designed a fuzzy rule base seizure detection system which is based on the expert's reaching knowledge [12]. Zarandi et al. have developed a type two fuzzy rule based expert system for the analysis of stock price. In this model, the technical and fundamental indexes are used as input variables. This model is also validated on stock price estimation of an automotive manufactory in Asia [13].

Fernandez et al. used a preprocessing step to deal with class imbalance in a fuzzy rule based classification system. They analyzed the behavior of fuzzy rule base classification system in the framework of datasets with the application of an adaptive inference system along with parametric conjugative system [14]. Fernandez et al. tried to improve the performance of fuzzy rule based classification systems like imbalanced domains, increased the granularity of the fuzzy partitions in the boundary areas between the classes and proposed the use of hierarchical fuzzy rule base classification system i.e. based on the refinement of a simple linguistic fuzzy method by using the extension of the structure of the knowledge based in a hierarchical way and used a genetic rule selection process by which a compact and accurate model is achieved [15]. Quek et al. described the application of a specific class of neuro fuzzy system which is known a Pseudo Outer Product Fuzzy Neural Network using Truth Value Restriction method (POPFNN-TVR) for modeling of traffic behavior. This model is highly applicable to the modeling of interlane relationship in a highway traffic stream and the results are better than the traditional system [16]. Chang and Liu introduced a Takagi-Sugeno-Kang(TSK) type fuzzy rule base system for the prediction of stock price. This model applied to the technical index because the input variable and the consequent parts is a linear combination of the input variables. This model tested on Taiwan electronic share from the Taiwan stock exchange (TSE) [17]. Taheri and Jahromi proposed a new learning rule for fuzzy rule based classification system. The method can be applied her single wiener of weighted vote methods of reasoning is used. The proposed method is much faster and more effective. The major advantage of this proposed method is that; the redundant rules are removed during the learning process [18]. Fernandez et al. studied the behavior of fuzzy rule base classification system in the scheme of imbalanced datasets, focusing on the synergy along with preprocessing mechanism of instances and the configuration of fuzzy rule datasets [19]. Ying and Pan predicted the regional electricity loads using adaptive network based fuzzy inference system. The objective of this study is to apply the Adaptive Network Based Fuzzy Inference System (ANFIS) model to predict the regional electricity loads and determine the predicting performance of this model [20]. Keshwani et al. developed two types of fuzzy models ( 3 inputs -1 output and 2 inputs -1 output) to detect the permeability of compounds through human skin. The information about the compound (molecular weight and octonal $-\mathrm{H}_{2} \mathrm{O}$ partition coefficient) and the application temperature are stored as an input. By comparing the predicted and actual fuzzy classification and defuzzification of the output compounds was quantify through this model to get crisp values for correlating estimates and published value [21]. Angelov has described a new approach to fuzzy rule based system structure identification in online mode. The author elaborated the previous approach i.e. TakajiSugeno (ETS) by introducing self learning aspects and also elaborate the mechanism of formation of new fuzzy sets and new fuzzy rules by using the online data density estimation [22]. Mansoori et al. considered the automatic design of fuzzy rule based classification system from the labeled data. The two main important fuzzy classification parameters are classification accuracy and interpretability of generated rules. The author proposed a weighting function for compatibility grade of patterns so that the performance fuzzy classification system was improved without degrading the interpretability of fuzzy rules [23]. Sun et al. investigated the accessibility of applying a novel neural network technique named as extreme learning machine (ELM) to estimate a neuro fuzzy Takaji-Sugeno-Kang (TSK) fuzzy inference system. This method is an updated version of regular neuro fuzzy TSH Fuzzy inference system. The proposed method has the 
advantage that eliminates the curse of diementiability i.e. measured in backpropagation and hybrid adaptive neuro fuzzy inference system [24]. Firat and Gungor used an Adaptive Network Based Fuzzy Inference System (ANFIS) approach to construct a river flow forecasting system. The river great Menderes which are located in the west of turkey is the most important water resource of great menderes catchment's was selected for the applicability and capability of ANFIS and found very imperative result of ANFIS upon the accuracy and reliability for river flow estimation [25]. Polat and Gunes detected on diabetes disease, which is an ordinary disease using Principal Component Analysis (PCA) and ANFIS. This study improves the accuracy of diagnosis diabetes disease using PCA and ANFIS [26].

Chang and Chang introduced a neuro fuzzy hybrid approach which is used in the construction of water level forecasting system during flood periods and used an ANFIS for the management of reservoir. The result of the presented study demonstrates that ANFIS can be successfully applied to the reservoir water level forecasting system and provide high accuracy results [27]. Polat and Gunes detected Adaptive Neuro Fuzzy Inference System (ANFIS) on thyroid disease using PCA, $\mathrm{k}$-nearest neighbor ( $\mathrm{k}-\mathrm{NN}$ ) based weighted preprocessing. This model consists of three stages. K-NN was utilized as a preprocessing step before the main classifier in the second stage. The Adaptive neuro fuzzy inference system was used in $3^{\text {rd }}$ stage for the diagnosis of thyroid disease [28]. Rong et al. introduced a Sequential Adaptive Fuzzy Inference System (SAFIS) which was based on the functional equality between a radial basis function network and a Fuzzy Inference System (FIS). The concept of "Influence" of a fuzzy rule is introduced in SAFIS system. In this method the fuzzy rules can be added or removed on the input data. "clasest" (in a Euclidean space sense) parameter was applied when the input data do not follow the adding of fuzzy rules. The closes rules are updated using an Extended Kalman Filter (EKF scheme) [29]. Kazeminezhad et al. predicted the wave performance of Adaptive Hardware Based Fuzzy Inference System (AHFIS) and Coastal Engineering Mahual (CEM). The data used in this study is fetched limited wave data. The result shows that AHFIS is more accurate in comparison to CEM method [30]. Guler and Ubeyli described the applicability of Adaptive Neuro Fuzzy Inference System (ANFIS) for the classification of electroencephalogram (EEG) signal. In this method the decision making was performed in two steps: One is feature extraction using the Wavelet Transform (WT) and the other one is ANFIS trained with backpropagation gradient descent method along with least square method. The performance of this model was evaluated in terms of training performance [31]. Chakraborty and Pal proposed a neuro fuzzy scheme for classifier designing along with feature selection. The network is trained in three phases in the first phase the important features and the classification rules are learn by the network whereas in the subsequent phase the, network represents an optimal set of rules. This system is tested on both synthetic and real set of data [32]. Lu and Antony proposed a method which has the advantage over Taguchi Method and fuzzy rule based inference system. This method is more robust and has the capability who tackles multiple response optimization problems [33]. Ho et al. proposed a method by using an Adaptive Neuro Fuzzy Inference System (ANFIS) which established a relationship between the surface image and the roughness of surface. This method effectively predicted the roughness of surface using cutting parameters (cutting speed, federate and depth of cut) and the gray level of surface image [34]. Kasabov introduced a new type of fuzzy inference system named as Dynamic Evolving Neural Fuzzy Inference System (DENFIS) for adaptive learning through online and offline and their application for dynamic time series prediction. DENFIS works though incremental, hybrid, learning and new data input, new features, new class through tuning of local elements. DENFIS effectively learns the complex sequences in an adaptive way and give the good results in comparison to other existing methods [35]. Cordon et al. proposed a method by which simple generation method is derived by Rule Base (RB) by using an appropriate Data Base (DB) by means of genetic algorithm [36]. Ishibuchi examined the effect of rule weights in fuzzy rule based classification system and used fuzzy reasoning method which based on single winner rule. The winner rule contains the pattern of fuzzy IF-THEN rule with the capability grade with new pattern. The author described the fuzzy IF-THEN rules with the help of drawing classification boundaries [37]. Chakrborty and Pal proposed a neuro fuzzy system which can simultaneously be done the feature analysis and system identification in an integrated manner. This method is a five layered feed forward network which is based on fuzzy rule based system. This system also maintained the non-negative characteristics of certainty factors of rule.

This system is validated on both synthetic and real data and results are quite satisfactory [38]. Cordon et al. proposed a new method in such rule base can be derived automatically through the knowledge base of a fuzzy rule based system by finding an appropriate database using genetic algorithm [39]. Casillas et al. presented a genetic feature selection process that can be used more efficiently to obtain a multistage genetic learning method. This proposed method affix, a prairie, elected the number of features, and accomplished, by using sonar example base [40]. Cordon et al. introduced new fuzzy reasoning method which is helpful in the improvement of system performance maintaining its interpretability and described the behavior of a general reasoning method, analyze six proposals for this general method and also presented a method to learn the various parameters of this fuzzy reasoning method [41]. Ishibuchi et al. examined two types of voting scheme based on fuzzy systems for the identification of pattern classification problems. In first type of voting machine, voting is done by multiple fuzzy if-then rules, I- a single fuzzy based classification system and the other type voting is done by multiple fuzzy rule based classification system [42]. Kuo and Xue utilized 
the fuzzy logic for learning process by using Fuzzy Neural Network (FNN) to grasp the expert's knowledge and proposed a system which consists of four parts; Data collection, general pattern model (ANN), unique pattern model (FNA), and decision integration (ANN). The findings from the proposed system indicated that this model could be performed more accurately as compared to other conventional statistical method and single ANN [43]. Czogala and Leski introduced a new artificial Neural Network Based Fuzzy Inference System (ANNBFIS). This system consist the moving fuzzy consequent if-then rules. The linear combination of system inputs are used to determine the location of the fuzzy set. This system automatically generates rules from the numerical data. The proposed system operated with Gaussian membership functions. Gradient and Least square methods were used for parameter estimation [44]. Tolias and Panas presented a new approach for upgrading the results of fuzzy clustering by applying spatial constraints for resolving the image segmentation problem. A sugeno (185) type rule-constructed system which takes three inputs and 11rules that connected with clustering results acquired by the well known Fuzzy C-Means (FCM) and Possibilistic C-Means (PCM) algorithm. It gives good image segmentation concerning area smoothness and removes noisy effect [45]. Bernard designed a rule based, digital, closed loop controller fuzzy logic and implemented it for the control of power on the 5-MWT Massachusetts Institute of Technology (MIT) research reactor under steady and transient conditions. The author compared the rule based and analytical approach based upon his previous experiences. The major advantage of the rule based system is that it is more robust than their analytical counter parts [46]. Jouffe concluded the Fuzzy Inference System (FIS). The learning process is the system feedback mechanism which is described in terms of reward and punishment task. In each step the agent received a signal according to the last action which was performed in the previous state. For the comparison of the methods, author used a well known Card-Pole Balancing and Mountain-Car Problems and focus on the important characteristics of Fuzzy Actor Critic Learning (FACL) and Fuzzy Q-Learning (FQL) [47]. Nozaki et al. proposed an adaptive method to build a fuzzy rule base classification system with high performance. This method contains two procedures: One is an error correction based learning process and the other one is additional learning process. In error correction based learning process; the grade of certainty of each fuzzy rule was adjusted. The authors also proposed a method for selection of significant fuzzy rule by processing unnecessary fuzzy rule and also constructed a compact fuzzy rule based classification with high performance [48]. Sun summarized the Jang's architecture of applied as adaptive network and the Kalman filtering algorithm to identify the system parameters. A date structure named as fuzzy binary boxtree was introduced which is helpful in the organization of rules so that the rule base can be matched to the input signals with logarithm efficiency [49]. Jang described the structure and learning process of ANFIS which is implemented in the framework of adaptive networks. The proposed ANFIS is constructed by a hybrid learning procedure in which input output mapping is done on both human knowledge and stipulated inputoutput data pairs [50].

\section{Proposed MOdEL FOR FuZZY INFERENCE SYSTEM}

The strategy here exhibited, as said recently, plans to help to make a choice about the changing a unit to a particular mission. As expressed before, a few parameters that impact such choice ought to be considered, this paper, however, goes for introducing an approach as opposed to formalizing the total choice system, in this way four delegate parameters have been taken into record and they have been distinguished by experts of military transport. Such parameters are the selection and maintenance of aim, efficiency of sub system, aim distance and sea condition. The efficiency of the framework associated with a mission is an essential concern since, as expressed recently, support operations are definitely restricted in seaward conditions. Moreover, the working states of frameworks and machinery must be considered as per the particular mission profile since specific number of machines is required in every mission. Hence it is to begin with expected to individuate the dispatch subsystems (Cooperation and Synergy, Concentration of Force, Morale Security, ammunition etc...) whose operability is required to achieve mission tasks. Additionally, for every subsystem, the components must be distinguished and their efficiency must be connected to the efficiency of the whole ship as per the useful relations communicated by the block diagram.

The FIS is applied to every subsystem by utilizing IFTHEN rules and fuzzy operators, to decide the effect of every subsystem on the operational preparation. At the last stage of the proposed methodology, by considering the minimum value among the output values, a measure of the ship operational status, with connection to a given mission, is provided. The less operator is selected to assure effectively perform mission undertakings.

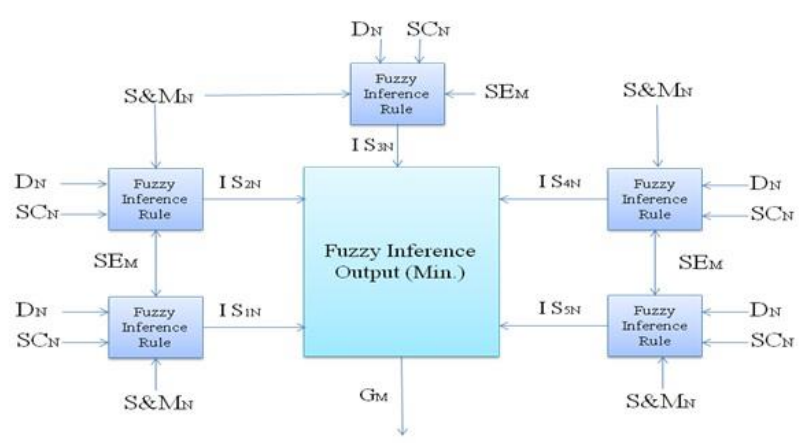

Fig.1. Model for Fuzzy Rule Based Inference System

Where,

$\mathrm{N}=$ Mission $/$ AIM

$\mathrm{M}=$ Subsystem 
$\mathrm{D}_{\mathrm{N}}=$ Distance to Aim

$\mathrm{SC}_{\mathrm{N}}=$ Sea Condition

$\mathrm{S} \& \mathrm{M}_{\mathrm{N}}=$ Selection and Maintenance of AIM

$\mathrm{SE}_{\mathrm{M}}=$ Efficiency of Subsystem $M$ with respect to the Mission/AIM

I $\mathrm{S}_{\mathrm{MN}}=$ Impact of subsystem $\mathrm{M}$ on the Mission/Aim N.

$\mathrm{G}_{\mathrm{M}}=$ Global Outcome exhibits the possibility of executing the Mission/AIM

A fundamental fuzzy logic system is constituted four segments: a rules set, a fuzzifier, a fuzzy inference engine and a defuzzifier. The center of a FIS is its knowledge base, which is demonstrated as fuzzy principles. Here the fuzzy logic system utilized multi input-single output system (MISO), utilizing the mamdani implications and the focal point of strategy as defuzzifier. At initial step of the inference procedure, it is expected to define the fuzzy set numbers to represent the crisp input values that are the fuzzification process, which comprises in allocating fuzzy semantic variables in the universe of each input value. Specifically, in this paper, each input parameter is depicted by triangular and trapezoidal fuzzy numbers.

\section{A. Triangular Fuzzy Number}

A fuzzy number $\tilde{\mathrm{A}}=\left(\mathrm{a}_{1}, \mathrm{a}_{2}, \mathrm{a}_{3}\right)$ is said to be triangular fuzzy number and interpreted as membership functions and holds the following conditions

(i) $a_{1}$ to $a_{2}$ is increasing function

(ii) $a_{2}$ to $a_{3}$ is decreasing function

(iii) $\mathrm{a}_{1} \leq \mathrm{a}_{2} \leq \mathrm{a}_{3}$.

$$
\mu_{(A)}(x)=\left\{\begin{array}{lc}
0, & \mathrm{x}<a_{1} \\
\frac{x-a_{1}}{a_{2}-a_{1}}, & a_{1} \leq \mathrm{x} \leq a_{2} \\
\frac{a_{3}-x}{a_{3}-a_{2}}, & a_{2} \leq \mathrm{x} \leq a_{3} \\
0, & \mathrm{x}>a_{3}
\end{array}\right.
$$

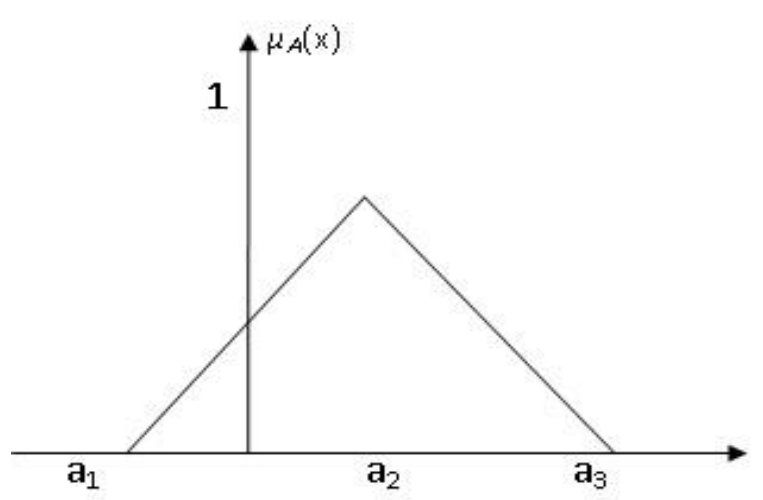

Fig.2. Triangular Fuzzy Number

\section{B. Trapezoidal Fuzzy Number}

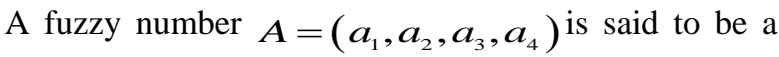
trapezoidal fuzzy number if its membership function interpreted as follows (Figure 3).

$$
\mu_{(A)}(x)=\left\{\begin{array}{lc}
0, & x<a_{1} \\
\frac{x-a_{1}}{a_{2}-a_{1}}, & a_{1} \leq x \leq a_{2} \\
1, & a_{2} \leq x \leq a_{4} \\
\frac{a_{4}-x}{a_{4}-a_{3}}, & a_{2} \leq x \leq a_{3} \\
0, & x>a_{4}
\end{array}\right.
$$

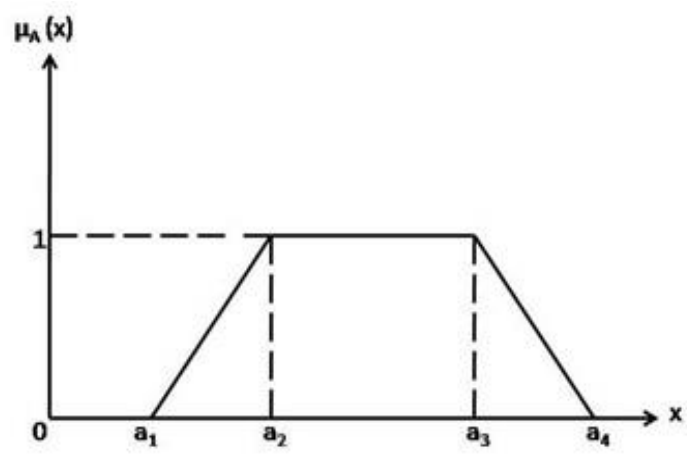

Fig.3. Trapezoidal Fuzzy Number

The next stage in the fuzzy logic system is to characterize the possible rules deriving from incorporating the fuzzy inputs. Principles are generally given by a group of specialists and are presented into the FIS. Afterward, since the value of the judgment parameters is crisp, the fuzzifier maps the input crisp numbers into the fuzzy sets to acquire degrees of membership. The inference engine of the FIS maps the forerunner fuzzy (IF part) sets into subsequent fuzzy sets (THEN part) considering the principles already expressed. The inference procedure decides the fuzzy subset of the output variable for each rule by utilizing the MIN operator (Mamdani operator) as suggestion operator. If more than one rule gives a similar outcome, an operator must aggregate the results of these rules. Specifically, the MAX operator is utilized. At last, the defuzzifier maps the fuzzy outcome into a crisp number, which turns into the outcome of the fuzzy logic system that is the effect of generic subsystem on ships operational preparation.

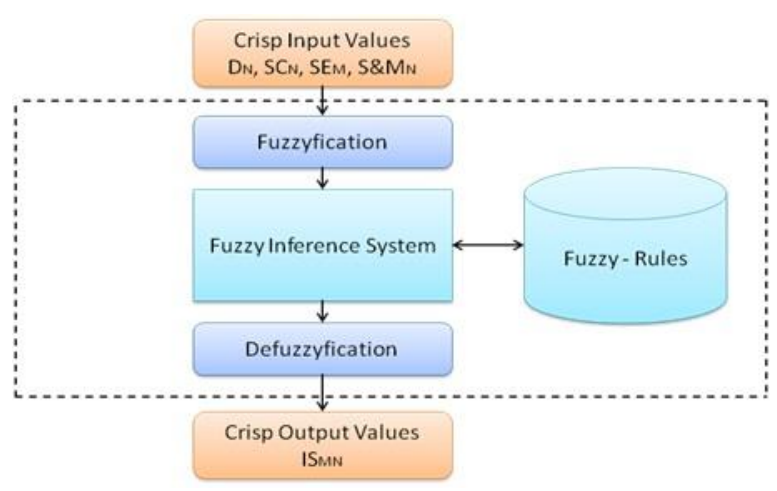

Fig.4. Block Diagram of FIS 


\section{IMPLEMENTATION OF PROPOSED MOdel}

The proposed technique is connected to a recreated case with connection to a military ship. The inference procedure is carried out by MATLAB. It is gathered that the ship is constituted by the accompanying subsystem individuated as basic for the mission's prosperity: cooperation and synergy, concentration of force, morale security, ammunition, and logistics. Such framework may experience distinctive stacking and business conditions in various missions' profiles with various dependability esteems. The reasonable structure here considered is consequently constituted by the frameworks dependability (concurring to the mission profile), the separation from the nearest port and the states of the ocean. Each input parameter has three linguistic variables (low, medium and high) as shown in figures 5, 6, 7 and 8 portrayed by triangular and trapezoidal fuzzy numbers, as appeared above. The output parameter has five linguistic factors (very low, low, medium, high and very high) has appeared in Figure 9.

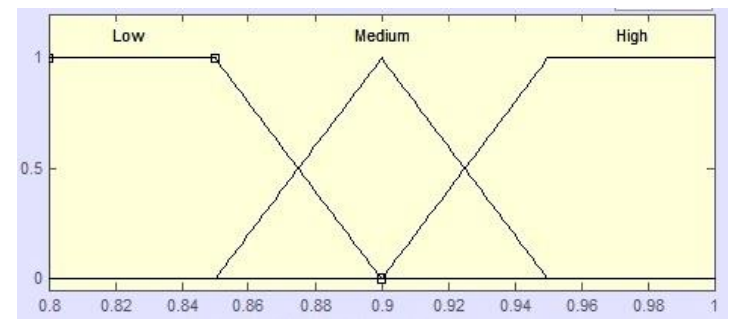

Fig.5. Selection and Maintenance of AIM

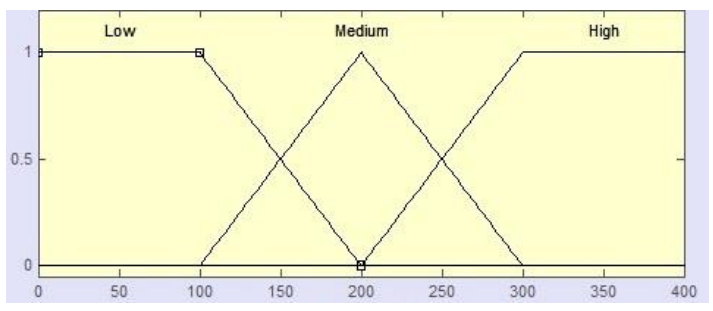

Fig.6. AIM Distance

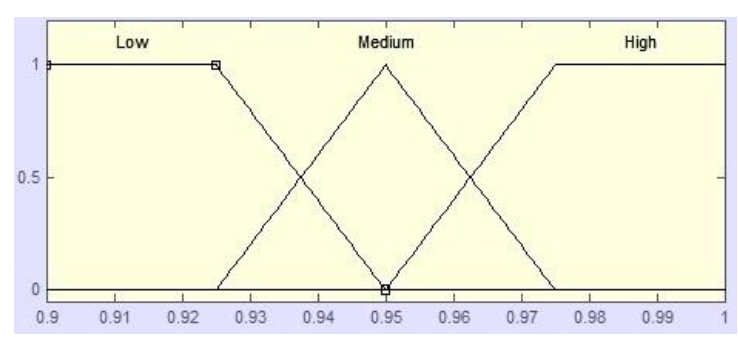

Fig.7. Subsystem Efficiency

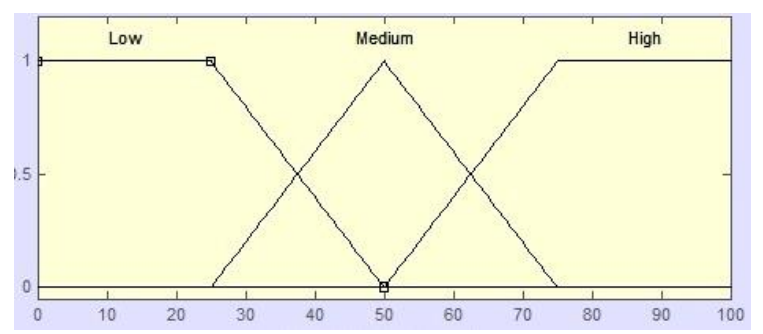

Fig.8. Sea Condition

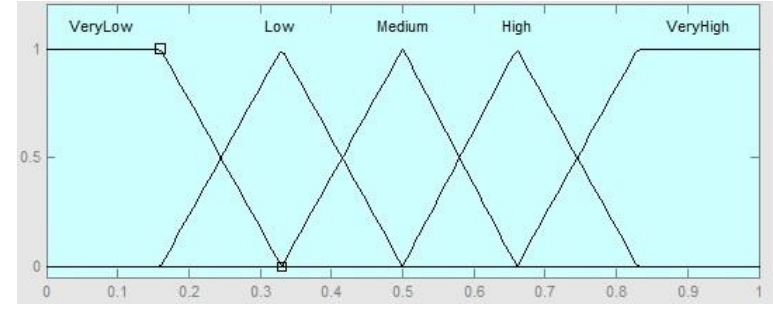

Fig.9. Impact on Successful Execution of Mission

The contribution of the generic subsystem $\mathrm{M}$ to the probability of executing the mission $\mathrm{IS}_{\mathrm{MN}}$ is communicated by values having a place with the range $[0$ 1] and it can be represented. The dependability of each subsystem for the mission $\mathrm{N}$, which constitutes a contribution to the decision framework, is given in Table1.The other input data of the mission $\mathrm{N}$ appear in Table-2. The set of standards individuated by the specialists given in Table-3.The related outcome got by the inference procedure are accounted for in Table-4. Subsequently, in this case, by applying the proposed strategy, that is by taking the minimum value among the output value, the ship operational preparation with connection to a given mission is measured in the range $[0,1]$.

Table 1. Subsystem Efficiency

\begin{tabular}{|c|c|}
\hline Subsystem & Efficiency \\
\hline Cooperation and Synergy & 0.98 \\
\hline Concentration of Force & 0.95 \\
\hline Morale Security & 0.92 \\
\hline Ammunition & 0.94 \\
\hline Logistics & 0.97 \\
\hline
\end{tabular}

Table 2. Other Mission Execution Input Parameters

\begin{tabular}{|c|c|c|}
\hline Selection and Maintenance of AIM & Distance & $\begin{array}{c}\text { Sea } \\
\text { Condition }\end{array}$ \\
\hline 0.92 & 250 & 60 \\
\hline
\end{tabular}

Table 3. Fuzzy Rules

\begin{tabular}{|c|c|c|c|c|}
\hline $\begin{array}{c}\text { Selection } \\
\text { and } \\
\text { Maintenance } \\
\text { of AIM }\end{array}$ & $\begin{array}{c}\text { Subsystem } \\
\text { Efficiency }\end{array}$ & $\begin{array}{c}\text { Distance } \\
\text { of AIM }\end{array}$ & $\begin{array}{c}\text { Sea } \\
\text { Condition }\end{array}$ & $\begin{array}{c}\text { Impact on } \\
\text { Mission } \\
\text { Execution } \\
\text { G }\end{array}$ \\
\hline L & L & L & L & L \\
\hline L & L & L & M & VL \\
\hline L & L & L & H & VL \\
\hline L & L & M & L & L \\
\hline L & L & M & M & VL \\
\hline L & L & M & H & VL \\
\hline L & L & H & L & L \\
\hline L & L & H & M & VL \\
\hline L & L & H & H & VL \\
\hline L & M & L & L & M \\
\hline L & M & L & M & M \\
\hline L & M & L & H & L \\
\hline L & M & M & L & M \\
\hline L & M & M & M & L \\
\hline L & M & M & H & VL \\
\hline L & M & H & L & VL \\
\hline
\end{tabular}




\begin{tabular}{|c|c|c|c|c|}
\hline $\mathrm{L}$ & $\mathrm{M}$ & $\mathrm{H}$ & M & VL \\
\hline $\begin{array}{l}\mathrm{L} \\
\end{array}$ & $\mathrm{M}$ & $\mathrm{H}$ & $\mathrm{H}$ & VL \\
\hline $\mathrm{L}$ & $\mathrm{H}$ & $\mathrm{L}$ & $\mathrm{L}$ & $\mathrm{H}$ \\
\hline $\mathrm{L}$ & $\mathrm{H}$ & $\mathrm{L}$ & $\mathrm{M}$ & $\mathrm{M}$ \\
\hline $\mathrm{L}$ & $\mathrm{H}$ & $\mathrm{L}$ & $\mathrm{H}$ & $\mathrm{M}$ \\
\hline $\mathrm{L}$ & $\mathrm{H}$ & $\mathrm{M}$ & $\mathrm{L}$ & $\mathrm{M}$ \\
\hline $\mathrm{L}$ & $\mathrm{H}$ & $\mathrm{M}$ & $\mathrm{M}$ & $\mathrm{M}$ \\
\hline $\mathrm{L}$ & $\mathrm{H}$ & $\mathrm{M}$ & $\mathrm{H}$ & $\mathrm{M}$ \\
\hline $\mathrm{L}$ & $\mathrm{H}$ & $\mathrm{H}$ & $\mathrm{L}$ & $\mathrm{M}$ \\
\hline $\mathrm{L}$ & $\mathrm{H}$ & $\mathrm{H}$ & $\mathrm{M}$ & $\mathrm{M}$ \\
\hline $\mathrm{L}$ & $\mathrm{H}$ & $\mathrm{H}$ & $\mathrm{H}$ & VL \\
\hline $\mathrm{M}$ & $\mathrm{L}$ & $\mathrm{L}$ & $\mathrm{L}$ & $\mathrm{M}$ \\
\hline $\mathrm{M}$ & $\mathrm{L}$ & $\mathrm{L}$ & $M$ & $\mathrm{M}$ \\
\hline $\mathrm{M}$ & $\mathrm{L}$ & $\mathrm{L}$ & $\mathrm{H}$ & $\mathrm{L}$ \\
\hline $\mathrm{M}$ & $\mathrm{L}$ & M & $\mathrm{L}$ & M \\
\hline $\mathrm{M}$ & $\mathrm{L}$ & $\mathrm{M}$ & $\mathrm{M}$ & $M$ \\
\hline $\mathrm{M}$ & $\mathrm{L}$ & $\mathrm{M}$ & $\mathrm{H}$ & $\mathrm{L}$ \\
\hline M & L & $\mathrm{H}$ & $\mathrm{L}$ & $\mathrm{L}$ \\
\hline $\mathrm{M}$ & $\mathrm{L}$ & $\mathrm{H}$ & $\mathrm{M}$ & $\mathrm{L}$ \\
\hline $\mathrm{M}$ & $\mathrm{L}$ & $\mathrm{H}$ & $\mathrm{H}$ & $\mathrm{VL}$ \\
\hline $\mathrm{M}$ & $\mathrm{M}$ & $\mathrm{L}$ & $\mathrm{L}$ & $\mathrm{H}$ \\
\hline $\mathrm{M}$ & $\mathrm{M}$ & $\mathrm{L}$ & $M$ & $\mathrm{H}$ \\
\hline $\mathrm{M}$ & $\mathrm{M}$ & $\mathrm{L}$ & $\mathrm{H}$ & $M$ \\
\hline $\mathrm{M}$ & $\mathrm{M}$ & $\mathrm{M}$ & $\mathrm{L}$ & $\mathrm{M}$ \\
\hline $\mathrm{M}$ & $\mathrm{M}$ & $\mathrm{M}$ & $\mathrm{M}$ & $\mathrm{M}$ \\
\hline $\mathrm{M}$ & $\mathrm{M}$ & $\mathrm{M}$ & $\mathrm{H}$ & $\mathrm{L}$ \\
\hline $\mathrm{M}$ & $\mathrm{M}$ & $\mathrm{H}$ & $\mathrm{L}$ & $\mathrm{M}$ \\
\hline $\mathrm{M}$ & $\mathrm{M}$ & $\mathrm{H}$ & $\mathrm{M}$ & $\mathrm{M}$ \\
\hline $\mathrm{M}$ & $\mathrm{M}$ & $\mathrm{H}$ & $\mathrm{H}$ & $\mathrm{L}$ \\
\hline $\mathrm{M}$ & $\mathrm{H}$ & $\mathrm{L}$ & $\mathrm{L}$ & $\mathrm{H}$ \\
\hline $\mathrm{M}$ & $\mathrm{H}$ & $\mathrm{L}$ & $\mathrm{M}$ & $\mathrm{M}$ \\
\hline M & $\mathrm{H}$ & $\mathrm{L}$ & $\mathrm{H}$ & $\mathrm{M}$ \\
\hline $\mathrm{M}$ & $\mathrm{H}$ & $\mathrm{M}$ & $\mathrm{L}$ & M \\
\hline $\mathrm{M}$ & $\mathrm{H}$ & $\mathrm{M}$ & $\mathrm{M}$ & M \\
\hline $\mathrm{M}$ & $\mathrm{H}$ & $M$ & $\mathrm{H}$ & $\mathrm{M}$ \\
\hline $\mathrm{M}$ & $\mathrm{H}$ & $\mathrm{H}$ & $\mathrm{L}$ & $M$ \\
\hline $\mathrm{M}$ & $\mathrm{H}$ & $\mathrm{H}$ & $\mathrm{M}$ & $\mathrm{M}$ \\
\hline $\mathrm{M}$ & $\mathrm{H}$ & $\mathrm{H}$ & $\mathrm{H}$ & $\mathrm{L}$ \\
\hline $\mathrm{H}$ & $\mathrm{L}$ & L & L & $\mathrm{H}$ \\
\hline $\mathrm{H}$ & L & $\mathrm{L}$ & M & M \\
\hline $\mathrm{H}$ & $\mathrm{L}$ & $\mathrm{L}$ & $\mathrm{H}$ & $\mathrm{L}$ \\
\hline $\mathrm{H}$ & $\mathrm{L}$ & $M$ & $\mathrm{~L}$ & $\mathrm{H}$ \\
\hline $\mathrm{H}$ & $\mathrm{L}$ & $\mathrm{M}$ & $M$ & $\mathrm{M}$ \\
\hline $\mathrm{H}$ & $\mathrm{L}$ & $\mathrm{M}$ & $\mathrm{H}$ & $\mathrm{L}$ \\
\hline $\mathrm{H}$ & $\mathrm{L}$ & $\mathrm{H}$ & $\mathrm{L}$ & $\mathrm{L}$ \\
\hline $\mathrm{H}$ & $\mathrm{L}$ & $\mathrm{H}$ & M & $\mathrm{L}$ \\
\hline $\mathrm{H}$ & $\mathrm{L}$ & $\mathrm{H}$ & $\mathrm{H}$ & VL \\
\hline $\mathrm{H}$ & $\mathrm{M}$ & $\mathrm{L}$ & $\mathrm{L}$ & $\mathrm{H}$ \\
\hline $\mathrm{H}$ & $\mathrm{M}$ & $\mathrm{L}$ & $\mathrm{M}$ & $\mathrm{H}$ \\
\hline $\mathrm{H}$ & $\mathrm{M}$ & $\mathrm{L}$ & $\mathrm{H}$ & $\mathrm{M}$ \\
\hline $\mathrm{H}$ & $\mathrm{M}$ & $\mathrm{M}$ & $\mathrm{L}$ & $\mathrm{H}$ \\
\hline $\mathrm{H}$ & $\mathrm{M}$ & $\mathrm{M}$ & $M$ & $\mathrm{H}$ \\
\hline $\mathrm{H}$ & $\mathrm{M}$ & $\mathrm{M}$ & $\mathrm{H}$ & $\mathrm{M}$ \\
\hline $\mathrm{H}$ & $\mathrm{M}$ & $\mathrm{H}$ & $\mathrm{L}$ & $\mathrm{M}$ \\
\hline $\mathrm{H}$ & $\mathrm{M}$ & $\mathrm{H}$ & $\mathrm{M}$ & $\mathrm{M}$ \\
\hline $\mathrm{H}$ & $\mathrm{M}$ & $\mathrm{H}$ & $\mathrm{H}$ & $\mathrm{L}$ \\
\hline $\mathrm{H}$ & $\mathrm{H}$ & $\mathrm{L}$ & $\mathrm{L}$ & $\mathrm{VH}$ \\
\hline $\mathrm{H}$ & $\mathrm{H}$ & $\mathrm{L}$ & $\mathrm{M}$ & $\mathrm{H}$ \\
\hline $\mathrm{H}$ & $\mathrm{H}$ & $\mathrm{L}$ & $\mathrm{H}$ & $\mathrm{M}$ \\
\hline $\mathrm{H}$ & $\mathrm{H}$ & $\mathrm{M}$ & $\mathrm{L}$ & $\mathrm{H}$ \\
\hline $\mathrm{H}$ & $\mathrm{H}$ & $\mathrm{M}$ & M & M \\
\hline $\mathrm{H}$ & $\mathrm{H}$ & $M$ & $\mathrm{H}$ & $\mathrm{L}$ \\
\hline $\mathrm{H}$ & $\mathrm{H}$ & $\mathrm{H}$ & $\mathrm{L}$ & $\mathrm{H}$ \\
\hline $\mathrm{H}$ & $\mathrm{H}$ & $\mathrm{H}$ & $\mathrm{M}$ & $\mathrm{M}$ \\
\hline $\mathrm{H}$ & $\mathrm{H}$ & $\mathrm{H}$ & $\mathrm{H}$ & $\mathrm{L}$ \\
\hline
\end{tabular}

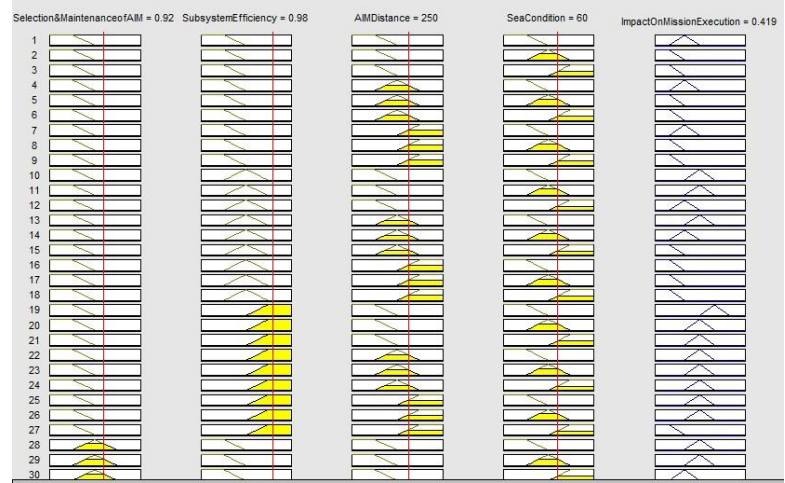

Fig.10. Impact of Cooperation and Synergy System

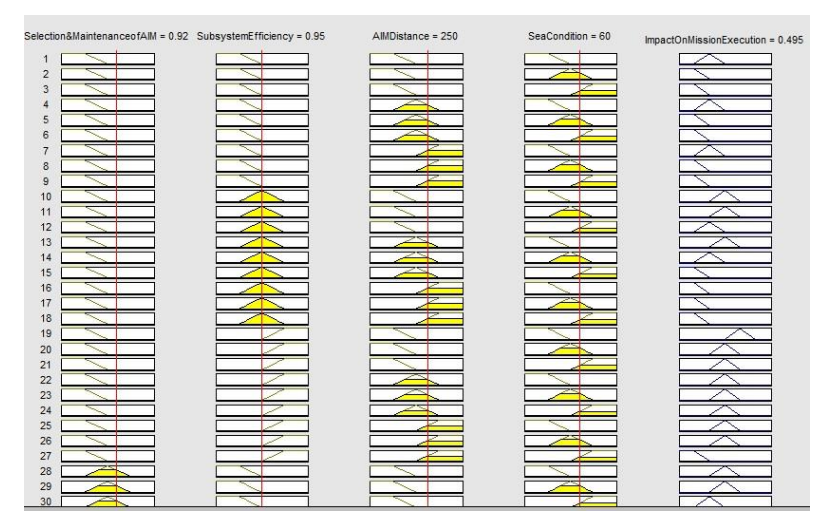

Fig.11. Impact of Concentration of Force System

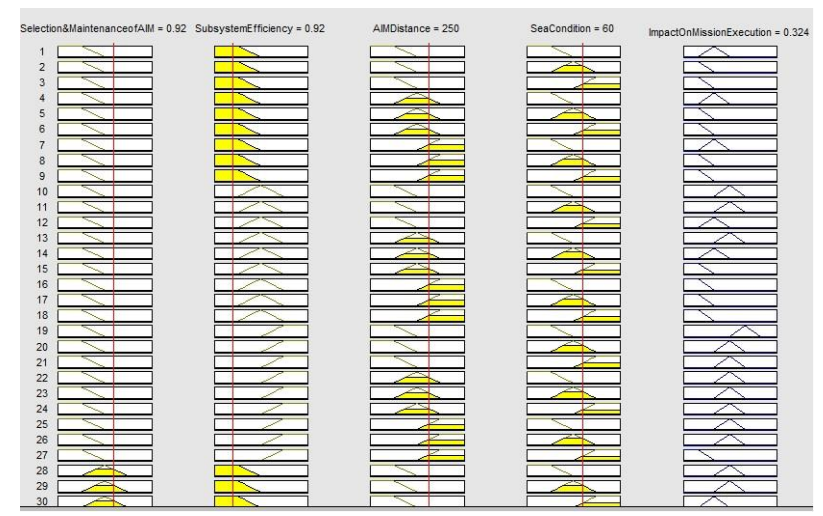

Fig.12. Impact of Morale Security System

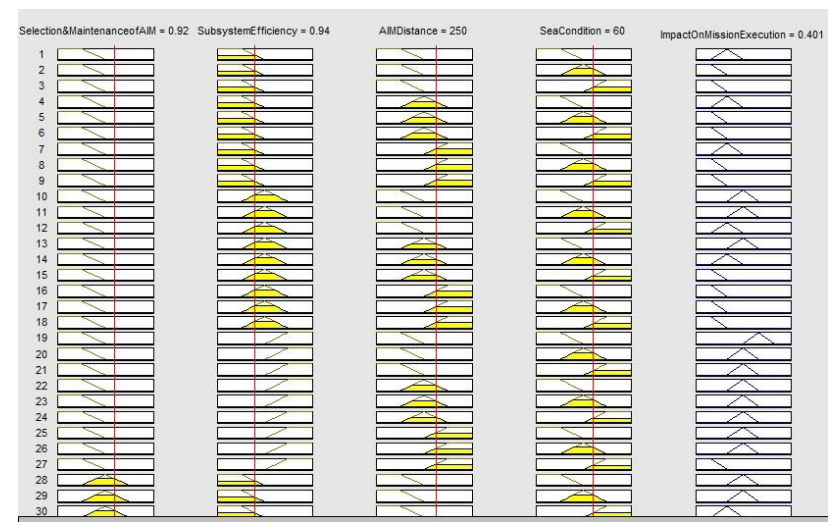

Fig.13. Impact of Ammunition System 


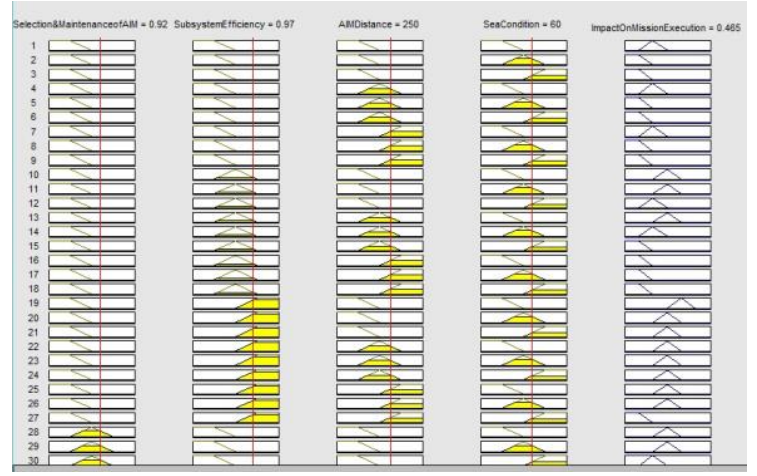

Fig.14. Impact of Logistics System

Table 4. Fuzzy Rules

\begin{tabular}{|c|c|}
\hline Subsystem & $\begin{array}{c}\text { Impact on Successful Execution } \\
\text { of Mission }\end{array}$ \\
\hline Cooperation and Synergy & 0.419 \\
\hline Concentration of Force & 0.495 \\
\hline Morale Security & 0.324 \\
\hline Ammunition & 0.401 \\
\hline Logistics & 0.465 \\
\hline
\end{tabular}

\section{RESUltS}

The impact of each subsystem on mission success is calculated by applying various fuzzy rules in fuzzy inference system. In this system, we have taken five different subsystem efficiency parameters and three basic mission executing input parameters to calculate the outcome of our fuzzy inference system. The subsystem parameters are cooperation and synergy, concentration of force, morale security, ammunition and logistics. We put these subsystem parameters with basic mission input parameters that are selection and maintenance of AIM, distance and sea condition. We put selection and maintenance of AIM is 0.92, distance is 250, seacondition is 60 with different subsystem efficiency parameters. After processing all these basic inputs with each subsystem inputs in fuzzy inference system the outcome is generated.

The impact of cooperation and synergy on mission is 0.419 when cooperation and synergy is 0.98 as shown in Fig.10, similarly the impact of concentration of force on mission is 0.495 when concentration of force is 0.95 as shown in Fig.11, the impact of morale security on mission is 0.324 when morale security is 0.92 as shown in Fig.12, the impact of ammunition on mission is 0.401 when ammunition is 0.94 as shown in Fig.13 and impact the of logistics on mission is 0.465 when logistics is 0.97 as shown in Fig. 14.

\section{CONCLUSIONS}

In this paper, the process of decision making that brings into service a military naval unit to a mission has been recognized. Such decision making process normally soliciting a human intelligence system includes knowledge about natural conditions, the working status of ammunition and so on. Such data cannot really validate by methods for customary (fresh) numerical models, because of its ambiguity and vulnerability, though such attributes can be productively considered utilizing estimated thinking. In this present paper, a specialist choice help in light of a fuzzy inference system is displayed, which permits to consider specialists' involvement in the judgments of the probability of a military naval unit playing out a mission. The mission is portrayed by a particular mission profile which characterizes the mission beginning and consummation time, and the arrangement of subsystem included. The numerical application introduced demonstrates that the approach displayed may effectively be utilized to help the chief in the choice based procedure giving a worldwide score communicating the probability of the ship to play out the mission assignments, consequently affirming the viability of fuzzy inference system in choice based examination.

\section{REFERENCES}

[1] Singh K., "Fuzzy Logic Based Modified Adaptive Modulation Implementation for Performance Enhancement in OFDM Systems", International Journal of Intelligent Systems and Applications, vol. 8(5), pp.4954, 2016.

[2] Mustapha S. et al., "Sequential Adaptive Fuzzy Inference System Based Intelligent Control of Robot Manipulators", International Journal of Intelligent Systems and Applications, vol. 11, pp.49-56, 2014.

[3] Olugu E.U., Wong K.Y., "An expert fuzzy rule-based system for closed-loop supply chain performance assessment in the automotive industry", Expert Systems with Applications, vol. 39(1), pp. 375-384, 2012.

[4] Akgun A. et al., "An easy-to-use MATLAB program (MamLand) for the assessment of landslide susceptibility using a Mamdani fuzzy algorithm", Computers \& Geosciences, vol. 38(1), pp. 23-34, 2012.

[5] Amindoust A. et al., "Sustainable supplier selection: A ranking model based on fuzzy inference system", Applied Soft Computing, vol. 12(6), pp. 1668-1677, 2012.

[6] Singh M., Chandra A., "Application of adaptive networkbased fuzzy inference system for sensorless control of PMSG-based wind turbine with nonlinear-loadcompensation capabilities", IEEE transactions on power electronics, vol. 26(1), pp. 165-175, 2011.

[7] Büyüközkan G., Çifçi G., "A novel fuzzy multi-criteria decision framework for sustainable supplier selection with incomplete information", Computers in Industry, vol. 62(2), pp. 164-174, 2011.

[8] Fernández A. et al., "Solving multi-class problems with linguistic fuzzy rule based classification systems based on pair wise learning and preference relations", Fuzzy sets and systems, vol. 161(23), pp. 3064-3080, 2010.

[9] Ustundag A. et al., "Fuzzy rule-based system for the economic analysis of RFID investments", Expert systems with applications, vol. 37(7), pp. 5300-5306, 2010.

[10] Kurnaz S. et al., "Adaptive neuro-fuzzy inference system based autonomous flight control of unmanned air vehicles", Expert Systems with Applications, vol. 37(2), pp. 1229-1234, 2010.

[11] Boyacioglu M.A., Avci D., "An adaptive network-based fuzzy inference system (ANFIS) for the prediction of stock market return: the case of the Istanbul stock 
exchange", Expert Systems with Applications, vol. 37(12), pp. 7908-7912, 2010.

[12] Aarabi A. et al., "A fuzzy rule-based system for epileptic seizure detection in intracranial EEG", Clinical Neurophysiology, vol. 120(9), pp. 1648-1657, 2009.

[13] Zarandi M.F. et al., "A type-2 fuzzy rule-based expert system model for stock price analysis", Expert Systems with Applications, vol. 36(1), pp. 139-154, 2009.

[14] Fernández A. et al., "Hierarchical fuzzy rule based classification systems with genetic rule selection for imbalanced data-sets", International Journal of Approximate Reasoning, vol. 50(3), pp.561-577, 2009.

[15] Fernández A. et al., "On the influence of an adaptive inference system in fuzzy rule based classification systems for imbalanced data-sets", Expert Systems with Applications, vol. 36(6), pp. 9805-9812, 2009.

[16] Quek C. et al., “A novel self-organizing fuzzy rule-based system for modelling traffic flow behavior", Expert Systems with applications, vol. 36(10), pp. 12167-12178, 2009.

[17] Chang P.C., Liu C.H., "A TSK type fuzzy rule based system for stock price prediction", Expert Systems with applications, vol.34 (1), pp. 135-144, 2008.

[18] Jahromi M.Z., Taheri M., "A proposed method for learning rule weights in fuzzy rule-based classification systems", Fuzzy Sets and Systems, vol. 159(4), pp. 449459, 2008.

[19] Fernández A. et al., "A study of the behaviour of linguistic fuzzy rule based classification systems in the framework of imbalanced data-sets", Fuzzy Sets and Systems, vol. 159(18), pp. 2378-2398, 2008.

[20] Ying L.C., Pan M.C., "Using adaptive network based fuzzy inference system to forecast regional electricity loads", Energy Conversion and Management, vol. 49(2), pp. 205-211, 2008.

[21] Keshwani D.R. et al., "Rule-based Mamdani-type fuzzy modeling of skin permeability", Applied Soft Computing, vol. 8(1), pp. 285-294, 2008.

[22] Angelov P. and Zhou X., "On line learning fuzzy rulebased system structure from data streams", IEEE International conference on fuzzy systems (FUZZ2008), pp. 915-922, 2008.

[23] Mansoori E.G., et al., “A weighting function for improving fuzzy classification systems performance", Fuzzy sets and systems, vol. 158(5), pp. 583-591, 2007.

[24] Sun Z.L. et al., "A neuro-fuzzy inference system through integration of fuzzy logic and extreme learning machines", IEEE Transactions on Systems, Man, and Cybernetics, Part B (Cybernetics), vol. 37(5), pp. 13211331, 2007.

[25] Firat M., Güngör M., "River flow estimation using adaptive neuro fuzzy inference system", Mathematics and Computers in Simulation, vol. 75(3), pp. 87-96, 2007.

[26] Polat K., Güneş S., "An expert system approach based on principal component analysis and adaptive neuro-fuzzy inference system to diagnosis of diabetes disease", Digital Signal Processing, vol. 17(4), pp. 702-710, 2007.

[27] Chang F.J., Chang Y.T., "Adaptive neuro-fuzzy inference system for prediction of water level in reservoir", Advances in water resources, vol. 29(1), pp. 1-10, 2006.

[28] Polat K., Güneş S., "A hybrid medical decision making system based on principles component analysis, k-NN based weighted pre-processing and adaptive neuro-fuzzy inference system", Digital Signal Processing, vol. 16(6), pp. 913-921, 2006.

[29] Rong H.J. et al., "Sequential adaptive fuzzy inference system (SAFIS) for nonlinear system identification and prediction", Fuzzy sets and systems, vol. 157(9), pp. 12601275,2006

[30] Kazeminezhad M.H. et al., "Application of fuzzy inference system in the prediction of wave parameters", Ocean Engineering, vol. 32(14), pp. 1709$1725,2005$.

[31] Güler I., Übeyli E.D., "Adaptive neuro-fuzzy inference system for classification of EEG signals using wavelet coefficients", Journal of neuroscience methods, vol. 148(2), pp. 113-121, 2005.

[32] Chakraborty D., Pal N.R., "A neuro-fuzzy scheme for simultaneous feature selection and fuzzy rule-based classification", IEEE Transactions on Neural Networks, vol. 15(1), pp.110-123, 2004.

[33] Lu D., Antony J., "Optimization of multiple responses using a fuzzy-rule based inference system", International Journal of Production Research, vol. 40(7), pp. 1613$1625,2002$.

[34] Ho S.Y. et al., "Accurate modeling and prediction of surface roughness by computer vision in turning operations using an adaptive neuro-fuzzy inference system", International Journal of Machine Tools and Manufacture, vol. 42(13), pp. 1441-1446, 2002.

[35] Kasabov N.K., Song Q., "DENFIS: dynamic evolving neural-fuzzy inference system and its application for timeseries prediction", IEEE transactions on Fuzzy Systems, vol. 10(2), pp. 144-154, 2002.

[36] Cordón O. et al., "Generating the knowledge base of a fuzzy rule-based system by the genetic learning of the data base", IEEE Transactions on fuzzy systems, vol. 9(4), pp.667-674, August 2001.

[37] Ishibuchi H., Nakashima T., "Effect of rule weights in fuzzy rule-based classification systems", IEEE Transactions on Fuzzy Systems, vol. 9(4), pp. 506-515, august 2001.

[38] Chakrborty D., Pal N.R., "Integrated feature analysis and fuzzy rule-based system identification in a neuro-fuzzy paradigm", IEEE Transactions on Systems, Man, and Cybernetics, Part B (Cybernetics), vol. 31(3), pp. 391-400, June 2001.

[39] Cordón O. et al., "A genetic learning process for the scaling factors, granularity and contexts of the fuzzy rulebased system data base", Information Sciences, vol. 136(1), pp. 85-107, 2001.

[40] Casillas J. et al., "Genetic feature selection in a fuzzy rulebased classification system learning process for highdimensional problems", Information Sciences, vol. 136(1), pp. 135-157, 2001.

[41] Cordón O. et al., "A proposal on reasoning methods in fuzzy rule-based classification systems", International Journal of Approximate Reasoning, vol. 20(1), pp. 21-45, 1999.

[42] Ishibuchi H. et al., "Voting in fuzzy rule-based systems for pattern classification problems", Fuzzy sets and systems, vol. 103(2), pp. 223-238, 1999.

[43] Kuo R.J., Xue K.C., "Fuzzy neural networks with application to sales forecasting", Fuzzy Sets and Systems, vol. 108(2), pp. 123-143, 1999.

[44] Łęski J., Czogała E., "A new artificial neural network based fuzzy inference system with moving consequents in if-then rules and selected applications", Fuzzy Sets and Systems, vol. 108(3), pp. 289-297, 1999.

[45] Tolias Y.A., Panas S.M., "On applying spatial constraints in fuzzy image clustering using a fuzzy rule-based system", IEEE Signal Processing Letters, vol. 5(10), pp.2 45-247, October 1998. 
[46] Bernard J.A., "Use of a rule-based system for process control", IEEE Control Systems Magazine, vol. 8(5), pp.313, October 1998.

[47] Jouffe L., "Fuzzy inference system learning by reinforcement methods", IEEE Transactions on Systems, Man, and Cybernetics, Part C (Applications and Reviews), vol. 28(3), pp. 338-355, 1998.

[48] Nozaki K. et al.,"Adaptive fuzzy rule-based classification systems", IEEE Transactions on fuzzy Systems, vol. 4(3), pp. 238-250,1996.

[49] Sun C.T., "Rule-base structure identification in an adaptive-network-based fuzzy inference system", IEEE Transactions on Fuzzy Systems, vol. 2(1), pp. 64-73, 1994

[50] Jang J.S., "ANFIS: adaptive-network-based fuzzy inference system", IEEE transactions on systems, man, and cybernetics, vol. 23(3), pp. 665-685, 1993.

\section{Authors' Profiles}

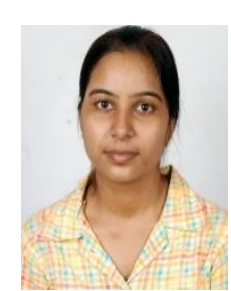

Rashmi Singh, Research Scholar in Department of Computer Science, Babasaheb Bhimrao Ambedkar University (A Central University), Lucknow, India. She has completed Master Degree in Computer Application in 2013 from Institute of Engineering \& Technology (IET), Lucknow, India affiliated to Uttar Pradesh Technical University, Lucknow (renamed as Dr. A.P.J. Abdul Kalam Technical University, U.P. Lucknow), INDIA. Her research interest is Fuzzy Cryptography, Software Engineering \& Security.

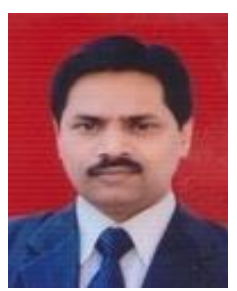

Dr. Vipin Saxena: Professor in Department of Computer science, Babasaheb Bhimrao Ambedkar University, Lucknow India. He got his M.Phil. Degree in Computer Application in 1992 \& Ph.D. Degree work on Scientific Computing from University of Roorkee (renamed as Indian Institute of Technology, Roorkee, India) in 1997. He has more than 20 years of teaching experience and 25 years research experience in the field of Scientific Computing \& Software Engineering. Currently he is proposing software designs by the use of Unified Modeling Language for the various research problems related to the Software and Hardware Domains. He has published more than 130 International and National publications.

How to cite this paper: Rashmi Singh, Vipin Saxena,"Fuzzy Rule Based Inference System for Implementation of Naval Military Mission", International Journal of Computer Network and Information Security(IJCNIS), Vol.10, No.4, pp.28-37, 2018.DOI: $10.5815 /$ ijcnis.2018.04.04 